\title{
BMJ Open Can we reduce costs and prevent more unintended pregnancies? A cost of illness and cost-effectiveness study comparing two methods of EHC
}

\section{Christine M Thomas, ${ }^{1}$ Sharon Cameron ${ }^{2}$}

To cite: Thomas CM, Cameron S. Can we reduce costs and prevent more unintended pregnancies? A cost of illness and costeffectiveness study comparing two methods of EHC. BMJ Open 2013;3: e003815. doi:10.1136/ bmjopen-2013-003815

- Prepublication history and additional material for this paper is available online. To view these files please visit the journal online (http://dx.doi.org/10.1136/ bmjopen-2013-003815).

Received 14 August 2013 Revised 13 November 2013 Accepted 18 November 2013

CrossMark

\footnotetext{
${ }^{1}$ Cambridge, UK

${ }^{2}$ Chalmers Sexual and Reproductive Health Centre, Edinburgh, UK
}

\section{Correspondence to} Christine M Thomas; christine.m.thomas@talk21. com

\section{ABSTRACT}

Objectives: To calculate the cost of an unintended pregnancy in 2011 and use this cost in a costeffectiveness model comparing ulipristal acetate (UPA) with levonorgestrel (LNG) for emergency hormonal contraception (EHC).

Design: Retrospective analysis of published data sources and published cost-effectiveness model.

Setting: Women presenting in primary care in England for EHC within 24 or $72 \mathrm{~h}$ of unprotected sexual intercourse (UPSI).

Interventions: EHC of either LNG $(1.5 \mathrm{mg})$ or UPA (30 mg).

Primary and secondary outcome measures: The primary outcome measure is the number and direct and indirect costs of an unintended pregnancy. The secondary outcome measure is the consequence of unintended pregnancy: miscarriage, abortion, ectopic pregnancy, stillbirth or live birth.

Results: From the comparative clinical studies of EHC we observe that if 125 women receive either LNG or UPA within $72 \mathrm{~h}$ of UPSI, there will be one less pregnancy due to method failure in the UPA group than in the LNG group. We calculate the cost of an unintended pregnancy to be $£ 1663$ in direct healthcare costs rising to £2922 with the inclusion of social costs. Using these costs in the comparative cost-effectiveness model shows that it costs $£ 194$ less in direct health costs alone to prevent one more pregnancy with UPA than with LNG. The inclusion of social costs of pregnancy increases this cost-saving potential to $£ 1453$ for each extra pregnancy avoided with UPA compared with LNG.

Conclusions: Clinical trials have demonstrated the superior efficacy of UPA compared with LNG as a method of EHC. Given that it costs less overall in health and social costs of pregnancy while preventing more pregnancies, UPA is said to be the dominant treatment, and primary care services should shift to offering UPA as the preferred oral option to women presenting within 24 and $72 \mathrm{~h}$ of UPSI.

\section{INTRODUCTION}

According to the government's Sexual Health Framework, around $50 \%$ of all
Strengths and limitations of this study

- We analysed published data sources from the National Health Service (NHS) and the government agencies to calculate the actual health and social costs incurred by pregnant women in 2011.

- Women who experience an unintended pregnancy may in fact incur higher health costs than those who plan a pregnancy, so our estimates may be an underestimate of the cost of unintended pregnancies.

- We predict savings that could occur in women presenting for emergency hormonal contraception although many women do not present to the healthcare system until the pregnancy is confirmed.

pregnancies are unplanned. The government's ambition is to reduce unintended pregnancies among all women of fertile age through increased knowledge and awareness of all methods of contraception and improved access to these methods, including emergency hormonal contraception (EHC), for women of all ages and their partners. The Sexual Health Framework concludes that "emergency contraception is a safe and effective way of preventing unwanted pregnancy when regular methods have failed or have not been used."1

Reduction in teenage pregnancy is one of the indicators of the government's Public Health Outcomes Framework ${ }^{2}$ and this age-group has the highest rate of abortions. ${ }^{3}$ Despite this focus, the rate of abortions has not reduced dramatically even with the free availability of contraception in the UK and a greater access to EHC in the recent years. However, $46 \%$ of the consultations for EHC at family planning clinics in 2011/2012 were in teenagers and $37 \%$ of EHC consultations were in those aged $16-19$ years. ${ }^{4}$

A study of unintended pregnancy and contraceptive use in Scotland found that less 
than $12 \%$ of those attending for abortion had used EHC. ${ }^{5}$ From the end of 2008, EHC has been available free of charge from pharmacies in Scotland, and a small decrease in abortions has been observed there. ${ }^{6}$ Women presenting for EHC are clearly indicating that they do not wish to become pregnant, despite being at risk of pregnancy following unprotected sexual intercourse (UPSI). As such they are a population that presents into the healthcare system at a risk of having an unintended pregnancy which could be avoided. Although the copper intrauterine device (IUD) is recognised by healthcare professionals as the most effective method of emergency contraception (EC), ${ }^{7}$ over $95 \%$ of women who present after UPSI do not opt for an IUD as a method of EC. ${ }^{4}$ In this article, we specifically examine the population who present at risk of an unintended pregnancy and for whom there is a choice of EHC.

There are two methods of EHC available: levonorgestrel (LNG) $1.5 \mathrm{mg}$ which is indicated for EC if taken within $72 \mathrm{~h}$ of UPSI and ulipristal acetate (UPA) $30 \mathrm{mg}$ which is indicated for EC within $120 \mathrm{~h}$ of UPSI. ${ }^{8}$ The two drugs were directly compared in two randomised controlled trials (RCTs) among women presenting at family planning clinics including 10 in the UK, and UPA was observed to have a lower pregnancy rate than LNG whether it was taken within 24, 72 or $120 \mathrm{~h}$ of UPSI. These two RCTs were combined in a meta-analysis which showed that the differences in pregnancy rates observed were significant. ${ }^{9}$ We previously used this meta-analysis to examine the relative cost-effectiveness of the two methods, and we demonstrated that there was an additional cost incurred to prevent every additional unintended pregnancy that occurred as a result of the higher failure rate of $\mathrm{LNG} .{ }^{10}$ In this article, we extend our previous study to calculate the likely cost of an unintended pregnancy. We do this by using more recent and accurate costs of abortion, miscarriage or the delivery of a baby and by including the wider health and social care costs of pregnancy that were actually incurred in 2011 as published by national data sources.

\section{METHODS}

We calculate the costs of pregnancy incurred in 2011 by analysing published data sources on costs and outcomes of pregnancy. We took a wider perspective than in our original analysis to include the direct healthcare costs and the indirect social costs of all maternities to calculate the average cost of pregnancy. Since the outcome of an unintended pregnancy is more likely to be an abortion, the average cost of an unintended pregnancy will differ from that of an intended one. We apply the outcome probabilities of unintended pregnancy that were observed in clinical trials of EHC and studies conducted on pregnancy intention in women in the UK to calculate the cost of an unintended pregnancy. This cost is then used, in the same cost-effectiveness model we developed previously, ${ }^{10}$ to determine the incremental cost-effectiveness ratio (ICER) between the two alternative methods of EHC. We analyse the use and expenditure in 2011 on EHC to predict the possible cost savings that could be made by using a more effective method of EHC.

\section{Direct healthcare costs}

We examined published data sources to identify the number of pregnancy and healthcare events and their respective costs. We included the number of births recorded in National Health Service (NHS) hospitals, ${ }^{11}$ the number of abortions ${ }^{12}$ and the number of miscarriages and ectopic pregnancies. ${ }^{13}$ The cost of each pregnancy event was taken from the NHS National Schedule of Reference Costs $2011^{14}$ and includes the direct healthcare costs of managing each pregnancy whether it resulted in a miscarriage, abortion, ectopic pregnancy or delivery of a live or stillborn baby. These included community and hospital costs with the exception of additional general practitioner (GP) visits for pregnancy-related issues.

For the purposes of this analysis, we examined the routine healthcare costs that are incurred during the first year of a baby's life. These included the standard immunisation schedule for the baby, ${ }^{15}$ hospital admissions recorded for children under 1 year ${ }^{13}$ health visitor costs, ${ }^{14}$ community paediatric appointments ${ }^{16}$ and visits to the GP. ${ }^{17}{ }^{18}$ We also calculated the cost of Healthy Start vouchers that are provided to some pregnant women and their babies. ${ }^{17}$ In 2011, the government also funded Health in Pregnancy Grants, a payment of $£ 180$ which was given to all pregnant women at 20 weeks of gestation. Since this scheme is no longer in existence we have excluded this cost from our analysis.

\section{Social costs}

A pregnancy resulting in delivery gives rise to additional costs for society. The government subsidises employment costs to working women through Statutory Maternity Pay or Maternity Allowance and Sure Start maternity grants to unemployed pregnant women. Social welfare payments are given in the form of child benefit, working and child tax credit. We calculated the average cost of these maternity benefits per pregnant woman by dividing the total maternity costs spent in 2011 by the number of pregnant women in 2011. Other social benefits costs are incurred, such as social security payments, housing benefit and council tax rebates. We analysed the government expenditure on these benefits and calculated the proportion that was spent on pregnant women and children under 1 year in 2011.

\section{Proportion and cost of unintended pregnancies}

Women who become pregnant unintentionally may opt to continue with the pregnancy or terminate through planned abortion; spontaneous abortion may also occur. The studies conducted on pregnancy intention in British women conclude that around one-third of all 
pregnancies are unintended. ${ }^{5}{ }^{19}$ Since the proportions of the various outcomes of unintended pregnancy differ from those of intended pregnancy, we used the outcome proportions observed in the comparative clinical trial of the two methods of hormonal contraception in women who became pregnant following EHC. ${ }^{10}$ These proportions were applied to the cost of each event to provide a cost of unintended pregnancy. We also examined the effect of using the outcomes observed in clinical practice from the published studies in the sensitivity analysis.

\section{Cost-effectiveness of EHC}

We used the updated cost of unintended pregnancy in our cost-effectiveness model comparing UPA with LNG. ${ }^{10}$ In the original model, we used the cost of GP consultation for providing EHC. However, since EHC is now administered more often from pharmacy, we used the cost of a pharmacy consultation in our updated calculation. This model was based on the difference in pregnancy rates observed in the clinical trials comparing LNG with UPA. ${ }^{9}$ In our original article, we took the time period of women presenting up to $120 \mathrm{~h}$ after UPSI. However, in this article, we conducted this analysis based on the timeframe of women presenting up to $72 \mathrm{~h}$ after UPSI since in the clinical trials $90 \%$ of women presented within $72 \mathrm{~h}$ of UPSI. ${ }^{9}$ The cost-effectiveness analysis provides an ICER, which is the cost of preventing one additional pregnancy with one drug compared with another. If this figure is negative, it indicates that it costs less to avoid an additional pregnancy. An alternative interpretation of these figures using the number needed to treat (NNT) methodology is also presented.

\section{Sensitivity analysis}

Since the main components of the ICER are the cost of unintended pregnancy and the failure rate of EHC, we undertook some sensitivity analysis to see how altering the value of these components might change our findings. For the cost of unintended pregnancy we used the outcomes observed in the clinical practice of women's pregnancy intention to revise the cost of an unintended pregnancy. ${ }^{519}$ For the failure rate of EHC we used the rate observed in the women presenting within $24 \mathrm{~h}$ of UPSI, ${ }^{9}$ since in the clinical trials one-third of women presented for EHC in the first $24 \mathrm{~h}$ following UPSI. Increasingly, in clinical practice, women are presenting within $24 \mathrm{~h}$ of UPSI and often directly to a pharmacy with the advent of various pharmacy schemes.

\section{RESULTS}

\section{Direct health cost of a pregnancy}

There were over one million pregnancies recorded in 2011 at a cost of over $£ 3.9$ billion in England. This cost is calculated from the number of recorded events of pregnancies resulting in miscarriage, abortion, ectopic pregnancy or delivery of a live or stillborn baby, as shown in table 1 , multiplied by the cost per event taken

\begin{tabular}{|c|c|c|c|}
\hline & $\begin{array}{l}\text { Number } \\
\text { of events }\end{array}$ & $\begin{array}{l}\text { Cost } \\
\text { per event }\end{array}$ & Total cost \\
\hline Miscarriages & 114091 & $£ 554$ & $£ 63206414$ \\
\hline Abortions & 183052 & $£ 714$ & $£ 130699128$ \\
\hline $\begin{array}{l}\text { Ectopic } \\
\text { pregnancies }\end{array}$ & 10796 & $£ 1228$ & $£ 13257488$ \\
\hline Stillbirths & 3612 & $£ 3765$ & $£ 13599180$ \\
\hline Live births & 694048 & $£ 5337$ & $£ 3704226375$ \\
\hline Total & 1005599 & $£ 3903$ & $£ 3924988585$ \\
\hline
\end{tabular}

from the National Schedule of Reference of Costs 2011. ${ }^{14}$ A further breakdown of these calculations and the source documents are provided in online supplementary appendix A.

This means that the cost of a pregnancy, whether planned or not, was, on an average, $£ 3903$ in 2011 in direct healthcare management expenditures alone. However, these costs are only part of the total health expense of a pregnancy. In pregnancies that result in a delivery, further health and social costs are incurred for the mother and the baby. We estimate that an average of $£ 821 /$ child is spent on routine healthcare during the first year of life. This average cost is shown broken down by the various elements of healthcare costs for children in the first year (see online supplementary appendix B). This equates to a further $£ 551$ million in the most conservative estimate.

\section{Wider social costs of pregnancy}

The government expenditure on specific maternity benefits amounted to $£ 2.3$ billion in 2011. A further $£ 34$ billion was spent on tax credits and child benefit, although this was across all eligible children and not just for children under 1 year. Some pregnant women and their infants were also eligible for social security benefit, housing allowance and council tax rebates. On an average, the social cost for each woman delivering a baby was $£ 7095$ in 2011, as outlined in table 2 .

Further details of the cost calculations and source documents are provided in online supplementary appendix C.

\section{Number of unintended pregnancies}

Two studies in Scotland examining contraceptive use in unintended pregnancy showed that $90 \%$ of terminations, $8 \%$ of deliveries and $11 \%$ of miscarriages were the result of unintended pregnancy. ${ }^{5}{ }^{19}$ These studies also estimated that overall one-third of all pregnancies are unintended. A recent study conducted among women presenting for abortion found that the pregnancy was unintended in $86 \%$ of cases and only $6.8 \%$ of women continued the pregnancy. ${ }^{27}$ Applying the latter proportions to the number of pregnancy events in England in 2011 would suggest that almost a quarter of all pregnancies that occurred in 2011 were unintended. 
Table 2 Social costs of a pregnancy

\begin{tabular}{|c|c|c|c|}
\hline & $\begin{array}{l}\text { Expenditure } 2011 \\
\text { (Emillions) }\end{array}$ & $\begin{array}{l}\text { Average cost per } \\
\text { eligible recipient }\end{array}$ & $\begin{array}{l}\text { Average cost per } \\
\text { woman delivering }\end{array}$ \\
\hline Working Tax \& Child Tax Credit $^{20}$ & $£ 22309$ & $£ 5638$ & $£ 1847$ \\
\hline Child benefit ${ }^{21}$ & $£ 12283$ & $£ 1065$ & $£ 1065$ \\
\hline Statutory Maternity Pay (SMP) ${ }^{22}$ & $£ 1934$ & $£ 4972$ & $£ 2911$ \\
\hline Housing benefit costs & $£ 20130$ & $£ 4760$ & $£ 523$ \\
\hline Maternity allowance ${ }^{24}$ & $£ 301$ & $£ 1592$ & $£ 453$ \\
\hline Social security ${ }^{25}$ & $£ 82$ & $£ 590$ & $£ 124$ \\
\hline Sure start maternity grants ${ }^{26}$ & $£ 66$ & $£ 500$ & $£ 99$ \\
\hline Council tax rebates ${ }^{23}$ & $£ 4291$ & $£ 730$ & $£ 73$ \\
\hline Total & & & $£ 7095$ \\
\hline
\end{tabular}

\section{Cost of unintended pregnancies}

The results from the clinical trials between the two methods of EHC show that in women who became pregnant after EHC failure, $66 \%$ had abortions, $18 \%$ continued to delivery and $16 \%$ experienced a miscarriage ${ }^{10}$ Applying these percentages to the average cost of each of these outcomes and allowing for the rate of ectopic pregnancy and stillbirth seen in the general population gives a cost of an unintended pregnancy. Using these most conservative outcomes of unintended pregnancies, the average cost of an unintended pregnancy is $£ 1519$ in pregnancy healthcare costs alone and $£ 1663$ with the inclusion of the child healthcare costs in the first year. Incorporating the wider social costs brings the average cost of an unintended pregnancy to $£ 2922$ in 2011 . The breakdown of this calculation is provided in online supplementary appendix D.

\section{Cost-effectiveness of EHC}

Our 2010 analysis showed that, on an average, it costs £311 to prevent one extra pregnancy if UPA was used instead of LNG in women presenting for EHC. Using the lower estimate of our updated costs of unintended pregnancy shows that in fact at least $£ 194$ could actually be saved for each additional pregnancy avoided. Inclusion of the social costs of unintended pregnancy could lead to a saving of $£ 1453$ for each additional pregnancy avoided by providing UPA rather than LNG to women presenting for EHC. We also looked at the impact on the results for women presenting within $24 \mathrm{~h}$ of UPSI. These results are presented in table 3.

Further sensitivity analyses were undertaken using the cost of unintended pregnancy based on the outcomes observed in the clinical practice and by disaggregating the cost components, and all produced a negative ICER. This indicates the robustness of the cost-saving claim of using UPA rather than LNG. Full details of the costeffectiveness calculations and sensitivity analyses are provided in online supplementary appendix E.

\section{Number needed to treat}

A different way of interpreting the ICER is provided by NNT, which is defined by

\section{Difference in efficacy}

In the case of the difference between UPA and LNG in women presenting within $72 \mathrm{~h}$ of UPSI $\frac{1}{0.8 \%}=125$ women would need to be treated with UPA rather than LNG in order to prevent one extra pregnancy. Table 4 outlines the additional costs incurred of treating these

\section{Table 3 Estimates of ICER of UPA versus LNG in EHC}

\begin{tabular}{|c|c|c|c|c|c|}
\hline & \multicolumn{2}{|l|}{ UPA } & \multicolumn{2}{|l|}{ LNG } & \multirow[b]{2}{*}{ ICER $^{\star}$} \\
\hline & $\begin{array}{l}\text { Pregnancy } \\
\text { rate }(\%)\end{array}$ & All costs & $\begin{array}{l}\text { Pregnancy } \\
\text { rate }(\%)\end{array}$ & $\begin{array}{l}\text { All } \\
\text { costs }\end{array}$ & \\
\hline $\begin{array}{l}\text { 1. All healthcare costs of unintended pregnancy= } \\
£ 1663\end{array}$ & 1.4 & $£ 50.23$ & 2.2 & $£ 51.79$ & $-£ 194$ \\
\hline $\begin{array}{l}\text { 2. Health and social cost of unintended pregnancy= } \\
£ 2922\end{array}$ & 1.4 & $£ 67.86$ & 2.2 & $£ 79.48$ & $-£ 1453$ \\
\hline $\begin{array}{l}\text { 3. Pregnancy rate within } 24 \mathrm{~h} \text { of UPSI (with } \\
\text { healthcare cost of unintended pregnancy }=£ 1663 \text { ) }\end{array}$ & 0.9 & $£ 41.92$ & 2.5 & $£ 56.78$ & $-£ 929$ \\
\hline $\begin{array}{l}\text { 4. Pregnancy rate within } 24 \text { h of UPSI (health and } \\
\text { social care costs }=£ 2922 \text { ) }\end{array}$ & 0.9 & $£ 53.25$ & 2.5 & $£ 88.25$ & $-£ 2188$ \\
\hline
\end{tabular}




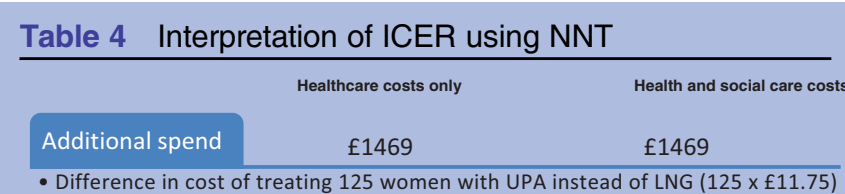

$\begin{array}{ll}\text { Avoided cost } & £ 1663 \\ \text { - Cost avoided by preventing an unintended pregnancy }\end{array}$

Net benefit

$-£ 194$

$-£ 1453$

- Additional drug cost minus the avoided health and social care costs

ICER, incremental cost-effectiveness ratio; LNG, levonorgestrel;

NNT, number needed to treat; UPA, ulipristal acetate.

125 women along with the costs saved by avoiding the additional unintended pregnancy. These net benefit figures are the same as the ICER and represent the budget impact of treating a population of 125 women with UPA rather than LNG and avoiding one additional unintended pregnancy.

\section{Net savings offered by a more effective EC}

Almost 245000 prescriptions were issued for EHC in the community in England in 2011 , costing $£ 1.3$ million. ${ }^{28}$ A further 128100 women obtained EHC directly from community contraception clinics. ${ }^{4}$ Owing to method failure, a small proportion of these 373094 women will still have become pregnant. Had these women been given UPA rather than LNG, almost 3000 additional pregnancies could have been averted, saving more than $£ 355000$ in healthcare costs and over $£ 4$ million in health and social costs, as shown in figure 1 . This is a conservative estimate of the potential savings since it does not include the women who obtain EHC directly from a pharmacy through patient group directions. Looking at the one-third of women who present within the first $24 \mathrm{~h}$ after UPSI, we found that an additional 2000 unintended pregnancies could have been avoided, saving over $£ 4.3$ million, as illustrated in figure 2 .
Details of the calculations of the budget impact of EHC provision in 2011 are given in online supplementary appendix $\mathrm{F}$.

\section{DISCUSSION}

We report the actual costs that were incurred by the NHS and government agencies to determine the average cost of pregnancy and subsequently the average cost of unintended pregnancy, rather than modelling the likely costs along a treatment pathway as we did in our 2010 study. We have also included all the costs of pregnancy, adding those related to management of pregnancy-related conditions and the neonatal period as well as health costs that are incurred by children during the first year of life. We did not include healthcare costs beyond the postnatal period for the mother.

Using the data from studies on women about pregnancy intention after contraceptive failure, we estimate that almost a quarter of all pregnancies in 2011 are unintended. Some authors have debated whether such pregnancies are truly unwanted as opposed to mistimed and preventing such a pregnancy defers, rather than prevents, the costs. ${ }^{29}$ However, women presenting for abortion are indicating that they do not wish to continue with the pregnancy and studies have shown that in almost $90 \%$ of women presenting for abortion, the pregnancy was unintended. ${ }^{27}$ In 2011, 36\% of women presenting for an abortion had terminated a previous pregnancy, the highest percentage over the last decade. ${ }^{12}$

There is increasing evidence that unintended pregnancies have poorer outcomes, and a recent review by the Academy of Medical Royal Colleges and the National Collaborating Centre for Mental Health concluded that unwanted pregnancy is associated with an increased risk of mental health problems. ${ }^{30}$ In addition, women who give birth following an unintended pregnancy may have a higher risk of postpartum depression, ${ }^{29}$ giving rise to higher health costs of an unintended pregnancy than those calculated in this article. Some women having an abortion experience complications, for example, pelvic infection or
Figure 1 Cost of giving all women who presented within $72 \mathrm{~h}$ after unprotected sexual intercourse (UPSI) alternative emergency hormonal contraception (EHC) in 2011.

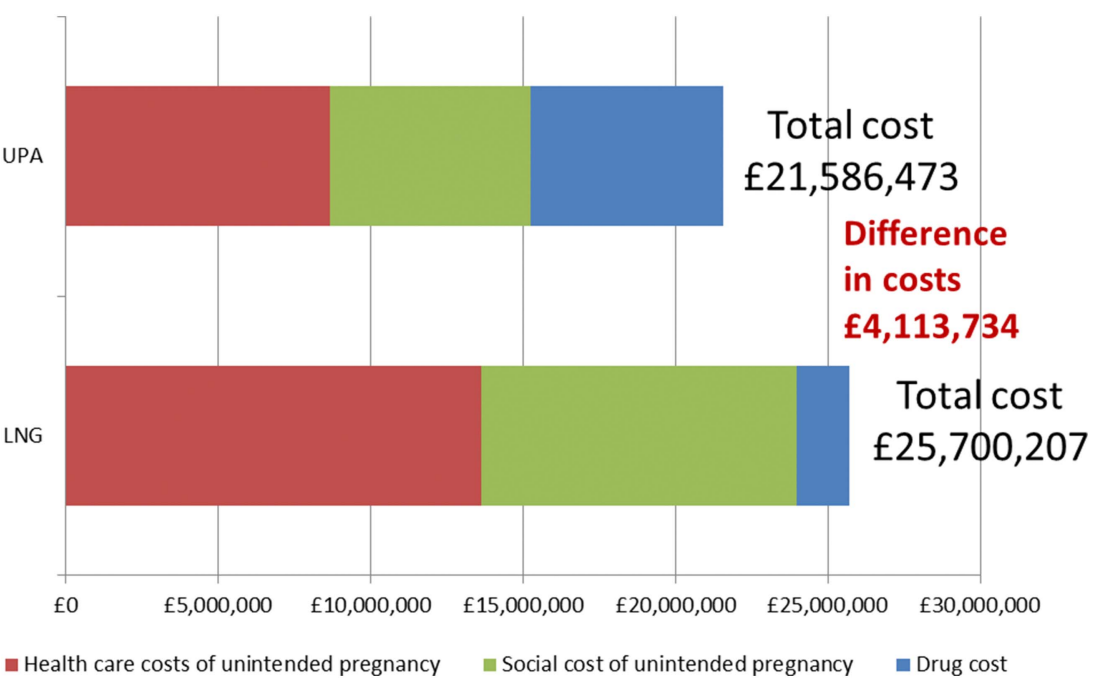


Figure 2 Cost of giving women who presented within the first $24 \mathrm{~h}$ after unprotected sexual intercourse (UPSI) alternative emergency hormonal contraception (EHC) in 2011.

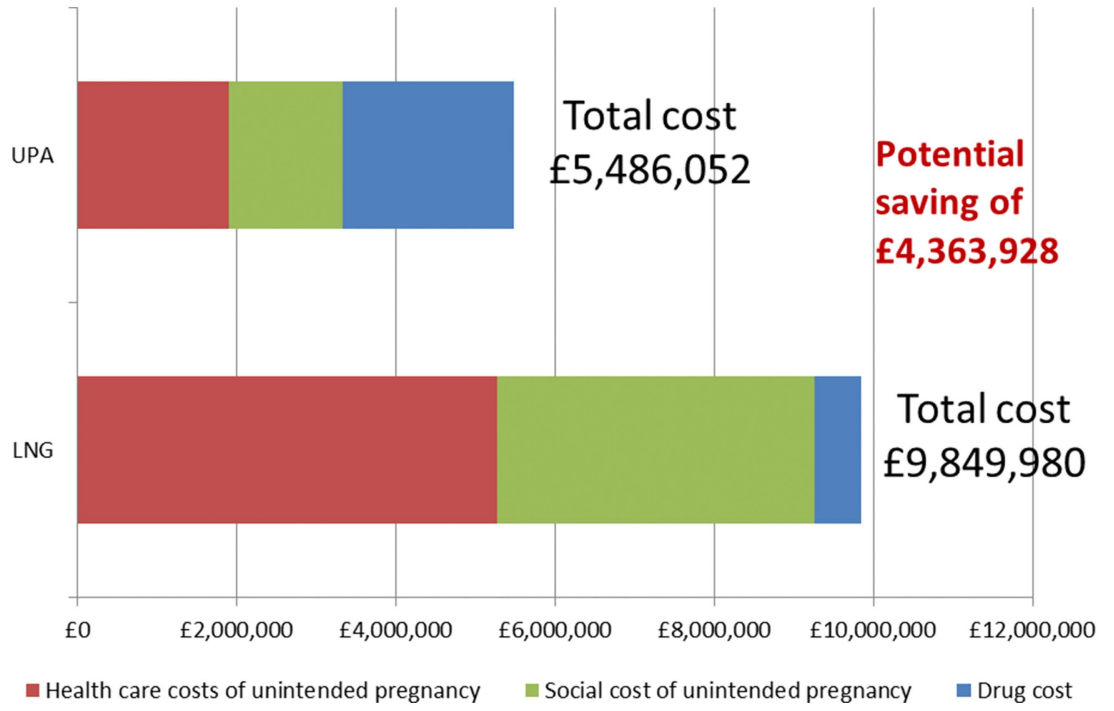

not the subsequent risk of unintended pregnancy if there are future episodes of UPSI.

The cost savings predicted in this study are based on a high proportion of women (almost 7 of 10) undergoing an induced abortion, with fewer continuing to delivery. However, in Northern Ireland and other parts of Europe such as Eire, abortion is only legally available under severely restrictive circumstances and women may have to continue the unintended pregnancy to delivery or travel for an abortion at a later and more costly stage. In such circumstances, even greater cost savings could be realised from the use of UPA for EHC.

If primary care services used UPA instead of LNG as the first choice for oral EHC to women presenting within the first $24 \mathrm{~h}$ of UPSI, over $£ 1.7$ million could have potentially been saved in direct healthcare costs while avoiding an additional 2000 unintended pregnancies. These potential savings present an opportunity to improve the access to sexual health services. The Department of Health published Commissioning Sexual Health Services and Interventions: Best Practice Guidance for Local Authorities ${ }^{32}$ earlier this year and concluded that EC is more effective the earlier it is used after unprotected sex. It also concluded that EHC should be made easily available and from a wide range of outlets.

While a shift from LNG to UPA as first-line EHC would require sexual health services to spend more of their drug budget on EHC, it should lead to fewer unintended pregnancies and net savings for the NHS overall.

\section{CONCLUSION}

We found, through the analysis of published data, that the NHS spent almost $£ 4$ billion on pregnancy healthcare in 2011. Inclusion of child health costs during the first year of life brings the total NHS healthcare costs to $£ 4.5$ billion. We estimate that unintended pregnancies cost over $£ 1$ billion. We calculated that the average cost per unintended pregnancy was £1519 in direct 
pregnancy healthcare costs, rising to $£ 1663$ if child health costs in the first year are included and totalling $£ 2922$ for all healthcare and social costs of unintended pregnancy in 2011. Using these updated estimates in our previous cost-effectiveness model comparing UPA with LNG, we conclude that UPA is a cost-saving alternative to LNG. This holds true for whichever perspective (healthcare only or health plus social care) is taken. The earlier the UPA was given after UPSI, the greater the cost-saving potential. With the wider availability of EHC through various pharmacy schemes, more women present directly to the pharmacy within the first $24 \mathrm{~h}$ after UPSI.

There is no evidence to support the assertion that improved access to EHC will reduce abortion rates. However, the population who do present for EHC (1) are at risk of pregnancy following UPSI, (2) are indicating that such a pregnancy is unintended and (3) are more likely to terminate the pregnancy if they subsequently become pregnant. Therefore, this population should be offered the most effective method available, especially if it has the potential to reduce healthcare budgets and achieve a reduction in the number of unintended pregnancies. Women who present into the healthcare system at risk of unintended pregnancy should be offered the most effective EHC as this could confer savings that could be invested elsewhere in sexual health services.

Acknowledgements The authors are grateful to Anna Glasier and Sharon Pfleger for their comments on earlier versions of the article and their guidance on sexual and public health priorities.

Contributors CMT conducted the cost analysis and drafted the manuscript methodology and results. SC was one of the original investigators in the clinical trials between ulipristal acetate (UPA) and levonorgestrel and provided input into the discussion section of the article about the management of women presenting for emergency hormonal contraception (EHC) in the clinical practice, the eligible population for EHC and she revised and approved the final draft.

Funding The study was funded by HRA Pharma UK \& Ireland Ltd, manufacturers of ellaOne (UPA).

Competing interests CMT has been paid by HRA Pharma Ltd, the manufacturer of UPA, for consulting on health economics. SC was principal investigator for the clinical studies of UPA, which were sponsored by HRA Pharma Ltd and has received lecture fees from HRA Pharma Ltd.

Provenance and peer review Not commissioned; externally peer reviewed.

Data sharing statement All data are published in the public domain and links to sources are provided in the reference list and appendices.

Open Access This is an Open Access article distributed in accordance with the Creative Commons Attribution Non Commercial (CC BY-NC 3.0) license, which permits others to distribute, remix, adapt, build upon this work noncommercially, and license their derivative works on different terms, provided the original work is properly cited and the use is non-commercial. See: http:// creativecommons.org/licenses/by-nc/3.0/

\section{REFERENCES}

1. Department of Health. A framework for sexual health improvement in England. March 2013.

2. Department of Health. Public health outcomes framework for England 2013 to 2016: improving outcomes and supporting transparency. 2012.
3. Department for Children, Schools and Families and the Department of Health. Teenage pregnancy strategy: beyond 2010. February 2010.

4. The Health and Social Care Information Centre. NHS contraceptive services: England, 2011/12. Lifestyles statistics. 31 October 2012.

5. Lakha F, Glasier A. Unintended pregnancy and use of emergency contraception among a large cohort of women attending for antenatal care or abortion in Scotland. Lancet 2006;368: 1782-7.

6. Glasier A. Emergency contraception: clinical outcomes. Contraception 2013;87:309-13.

7. Cleland K, Zhu H, Goldstuck N, et al. The efficacy of intrauterine devices for emergency contraception: a systematic review of 35 years of experience. Hum Reprod 2012;27:1994-2000.

8. British National Formulary (BNF) Joint Formulary Committee November 2013. London: BMJ Group and Pharmaceutical Press, 2013. http://www.bnf.org/

9. Glasier AF, Cameron ST, Fine PM, et al. Ulipristal acetate versus LNG for emergency contraception: a randomised non-inferiority trial and meta-analysis. Lancet 2010;375:555-62.

10. Thomas CM, Schmid R, Cameron S. Is it worth paying more for emergency contraception? The cost-effectiveness of ulipristal acetate versus LNG. J Fam Plann Reprod Health Care 2010;36:197-201.

11. Births in England and Wales by Characteristics of Birth 2, 2011. Office of National Statistics Statistical Bulletin. 7 February 2013.

12. Department of Health, Abortion Statistics, England and Wales: 2011 May 2012

13. Health \& Social Care Information Centre. Hospital episode statistics, 2011.

14. Department of Health, National Schedule of Reference Costs 2011-2012, 2012.

15. NHS Immunisation Statistics, England 2011-12. Health and Social Care Information Centre. 27 November 2012.

16. Prospectus for Children's Health Services Delivered in community settings. British Association for Community Child Health (BACCH). 12 October 2012

17. Lennox A, Sommerville J, Ong K, et al. Diet and Nutrition Survey of Infants and Young Children (DNSIYC), 2011. Department of Health. 11 March 2013.

18. Hippisley-Cox J. Trends in consultation rates in general practice -1995-2008. Health and Social Care Information Centre. 2 September 2009.

19. Schünmann C, Glasier A. Measuring pregnancy intention and its relationship with contraceptive use among women undergoing therapeutic abortion. Contraception 2006;73:520-4.

20. Child Benefit, Child Tax Credit and Working Tax Credit. Take-up rates 2010-11. HM Revenue and Customs KAI Benefits \& Credits. National Statistics, 2012

21. Child Benefit Statistics 2011. HM Revenue and Customs KAI Benefits \& Credits. National Statistics, 2012.

22. Benefit expenditure by country, region and local authority from 2000/ 01 to 2011/12. Department for Work and Pensions. 23 April 2013.

23. Housing Benefit and Council Tax Benefit expenditure by loca authority from 1996/97 to 2011/12. Department for Work and Pensions. 23 April 2013.

24. Maternity Allowance: quarterly statistics. Department for Work \& Pensions. 15 May 2013.

25. Annual Abstract of Statistics 2011: Chapter 5 Social Protection. Department of Work and Pensions. 2011 Office for National Statistics.

26. Summary of benefit expenditure 2010-11. Department of Work and Pensions.

27. Cameron ST, Glasier A. Identifying women in need of further discussion about the decision to have an abortion and eventual outcome. Contraception 2013;88:128-32.

28. Department of Health. Prescription cost analysis 2011. Health \& Social Care Information Centre, 2012.

29. Mercier RJ, Garrett J, Thorp J, et al. Pregnancy intention and postpartum depression: secondary data analysis from a prospective cohort. BJOG 2013;120:1116-22.

30. Induced abortion and mental health, Academy of Royal Medical Colleges, 2011.

31. Humby P. An analysis of under 18 conceptions and their links to measures of deprivation, England and Wales, 2008-10. Office of National Statistics; 14 February 2013.

32. Best practice guidance for local authorities: Commissioning Sexual Health services and interventions. Department of Health March 2013 Published to DH website, in electronic PDF format only. http://www. dh.gov.uk/publications 